Research Article

\title{
Study on Vibration Characteristics of Natural Gas Pipeline Explosion Based on Improved MP-WVD Algorithm
}

\author{
Huayuan Ma $\mathbb{D},{ }^{1}$ Yuan Long $\mathbb{D}^{1},{ }^{1}$ Xinghua Li, ${ }^{1}$ Mingshou Zhong $\mathbb{D},{ }^{1}$ Jianyuan $W u\left(\mathbb{D},{ }^{2}\right.$ \\ and You $\mathrm{Zhou}^{3}$ \\ ${ }^{1}$ Army Engineering University of PLA, Nanjing, China \\ ${ }^{2}$ PLA 75833 Force, Guangzhou, China \\ ${ }^{3}$ Northwest Institute of Nuclear Technology, Xi'an, China
}

Correspondence should be addressed to Yuan Long; long_yuan@sohu.com

Received 28 March 2018; Revised 18 June 2018; Accepted 4 July 2018; Published 1 August 2018

Academic Editor: Mickaël Lallart

Copyright (c) 2018 Huayuan Ma et al. This is an open access article distributed under the Creative Commons Attribution License, which permits unrestricted use, distribution, and reproduction in any medium, provided the original work is properly cited.

In order to meet the requirement of precise analysis of nature gas pipeline explosion, authors combined MP algorithm and WVD distribution to improve the time-frequency resolution and to solve the problem of cross-terms interference. The HHT algorithm was applied to the data preprocessing of MP algorithm to reduce the computational complexity of the MP algorithm. It improved the computing efficiency and laid the foundation for big data analysis. In this paper, authors carried out a full-size pipeline explosion experiment at the CNPC pipeline fracture control State Key Laboratory. Advantages of the improved MP-WVD algorithm were taken to obtain the time-frequency distribution characteristics of the pipeline explosion vibration. The research provided a new algorithm for the time-frequency distribution of nonstationary random vibration, and the result provided a reference for the safe operation and construction of natural gas pipeline.

\section{Introduction}

With the popularization of natural gas, the construction mileage of pipeline is increasing year by year. The explosion accidents of natural gas pipeline that occurred occasionally brought a variety of damage effects $[1,2]$. Shock wave and thermal radiation were the main damage effects to people, and a lot of research has been done at present [3-5]. The vibration wave, which mainly destroyed the buildings, has not been studied deeply yet. Taking the vibration signal generated by natural gas pipeline explosion as the research object, the authors improved the traditional time-frequency analysis algorithms and obtained more accurate timefrequency characteristics of the vibration.

At present, all the algorithms used in the field of timefrequency analysis had their own advantages and disadvantages. The STFT algorithm initially provided the possibility for Fourier transform to be applied to time-frequency analysis $[6,7]$. However, the bases of the algorithm were still trigonometric function, which could not match with the unsteady process of blasting vibration accurately. Da-chao et al. [8] analyzed an experimental recording signal of ground motion by means of Fourier transform, short-time Fourier transform (STFT), continuous wavelet (CWT), and discrete wavelet transform (DWT). The results showed that wavelet transform introduced the wavelet bases which were more suitable for vibration wave, but its time-frequency resolution was still limited by the uncertainty principle $[9,10]$. Renshu et al. $[11]$ did the comparison between HHT and short-time Fourier transformation (STFT) of blast wave signals, the HHT transform method proposed adaptive bases, but the interference of the EMD algorithm's boundary effect to the original signal was still a difficult problem. In the field of time-frequency analysis, the WVD distribution has an accurate time-frequency resolution, but its cross-term problem has plagued researchers for a long time $[12,13]$. With the indepth study, authors, combining HHT, MP, and WVD algorithms, solved the cross-term interference and reduced the complexity of the MP algorithm greatly, which laid the foundation for large amount of data analysis. Compared with the traditional algorithms (STFT, Wavelet, and HHT), this 
algorithm had higher time-frequency resolution and better algorithm efficiency.

\section{Basic Principle of Algorithm}

2.1. WVD Distribution. The WVD algorithm was first applied by Ville to the domain of time-frequency analysis. At the same time, Ville further demonstrated the Wegener Distribution. According to the eigenfunction method, he derived the WVD expression of the signal [14].

$$
W(t, \omega)=\frac{1}{2 \pi} \int x\left(t-\frac{1}{2} \tau\right) \cdot x\left(t+\frac{1}{2} \tau\right) e^{-j \tau \omega} d \tau .
$$

As can be seen from formula (1), there was no window function in the WVD expression of the signal. It also meant that there was no inverse relation between the frequency resolution and time resolution of WVD, which was not constrained by the Heisenberg uncertainty principle.

The distribution of WVD was nonlinear time-frequency distribution. Therefore, it did not have the additivity of linear distribution. That is, the WVD of the sum of two signals were not equal to the sum of the WVD of each signal.

$$
\begin{aligned}
X(t)= & X_{1}(t)+X_{2}(t), \text { then } \\
W(t, \omega)= & \frac{1}{2 \pi} \int\left[x_{1}\left(t+\frac{1}{2} \tau\right)+x_{2}\left(t+\frac{1}{2} \tau\right)\right] \\
& \cdot\left[x_{1}\left(t-\frac{1}{2} \tau\right)+x_{2}\left(t-\frac{1}{2} \tau\right)\right] e^{-j \tau \omega} d \tau \\
= & W_{x_{1}}(t, \omega)+W_{x_{2}}(t, \omega)+2 \operatorname{Re}\left[W_{x_{1}+x_{2}}(t, \omega)\right] .
\end{aligned}
$$

In the formula, $\operatorname{Re}\left[W_{x_{1}+x_{2}}(t, \omega)\right]$ was cross WVD of the $X_{1}(t)$ and $X_{2}(t)$, called cross term.

2.2. MP Algorithm. The principle of the MP algorithm was to decompose the signal based on the dictionary atoms. The process is shown in Figure 1 . The atom $Q_{n}$ with the highest matching degree to the signal $T_{n}$ was selected, and the projection value $T_{n}$ and the residual signal $T_{n+1}$ were found. After the residual signal $T_{n+1}$ was obtained, the process of atomic matching was repeated. $T_{n+1}$ was projected to the closest atom $Q_{n+1}$, and the residual signal $T_{n+2}$ was obtained. This cycle was repeated until the residual signal energy was less than the preset threshold [15], according to the actual needs of different accuracy of analysis.

\section{Defect and Improvement of the Algorithm}

As mentioned above, the existence of the cross terms had greatly disturbed the time-frequency distribution of the signal. Therefore, in this paper, the MP algorithm was used to subdivide the original signal into the basic atoms, and then calculated the WVD of each atom $[16,17]$. The calculation results were summed up and a clearer time-frequency distribution was obtained. Figure 2 was a synthetic sample signal.

The first method was to calculate its WVD directly. The second method was to calculate its WVD after subwave decomposition. The results obtained by the two methods were compared as shown in Figure 3.

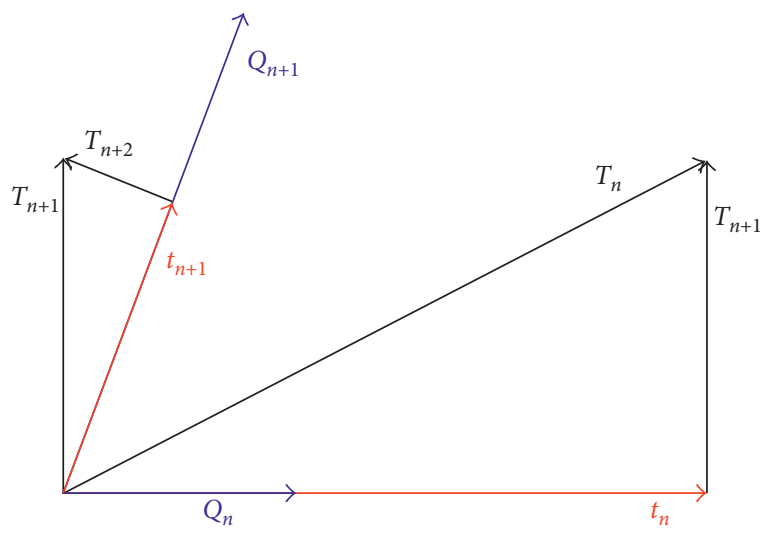

Figure 1: Algorithm schematic diagram.

As could be seen from the WVD time-frequency distribution, cross terms appeared at the middle points of the central connection of valid signals. This meant that the WVD transform would produce a cross term between any two valid signals. In Figure 3(a), the sample signal had 3 components, and a total of 3 cross terms were produced. That is to say, $N *(N-1) / 2$ crosses would be produced for $N$ components. However, in Figure 3(b), the subwave decomposition method was adopted to eliminate the interference of the cross terms successfully.

On the other hand, for the current research status, the biggest defect of the MP algorithm was the complexity. It took a long time to complete signal decomposition. The amount of data in the usual time-frequency analysis was very large, so the researchers hoped to get a more efficient algorithm by improving it.

The control parameters of the Gabor atom used in the MP algorithm were amplitude, frequency, central time, and phase. The process of scanning was the optimization of the four parameters by the exhaustive method. To simplify the calculation process, in this paper, the HHT method was introduced. The HHT method consists of two steps, the EMD algorithm and Hilbert transform.

Firstly, the signal $Z(t)$ was decomposed into multiple intrinsic modal functions $c(t)$ by EMD algorithm. Then a Hilbert transformation was performed on $c(t)$ :

$$
H[c(t)]=\frac{1}{\pi} \mathrm{PV} \int_{-\infty}^{\infty} \frac{c\left(t^{\prime}\right)}{t-t^{\prime}} d t^{\prime},
$$

where PV represents the Cauchy principal value. An analytic signal $z(t)$ was established:

$$
z(t)=c(t)+j H[c(t)]=a(t) e^{j \Phi(T)},
$$

where $a(t)$ is the amplitude function, and $\Phi(t)$ is the phase function

$$
\begin{aligned}
a(t) & =\sqrt{c^{2}(t)+H^{2}[c(t)]}, \\
\Phi(t) & =\tan ^{-1} \frac{H[c(t)]}{c(t)} .
\end{aligned}
$$

Further, the instantaneous frequency of the signal could be obtained by differentiating the phase function. Bringing the results into the MP algorithm, the 4 parameters (amplitude, 


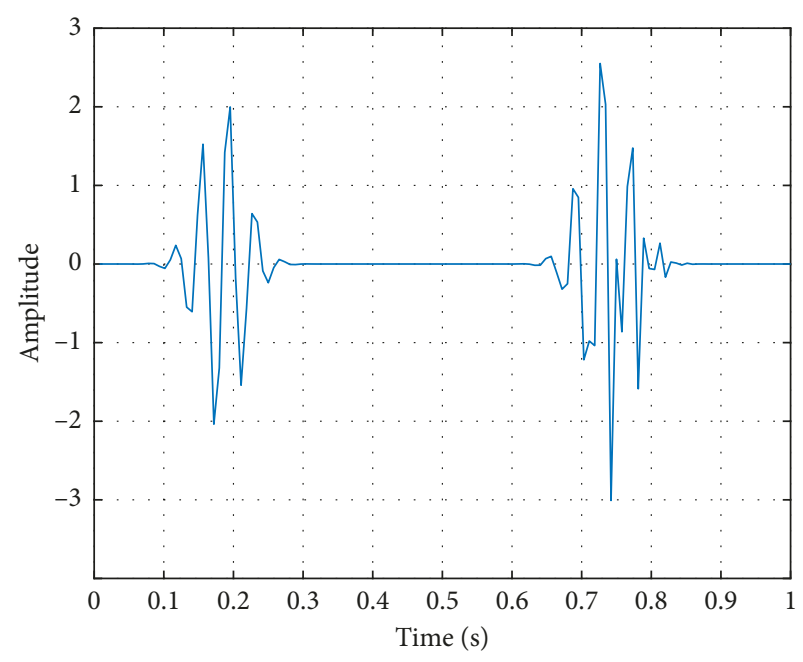

(a)
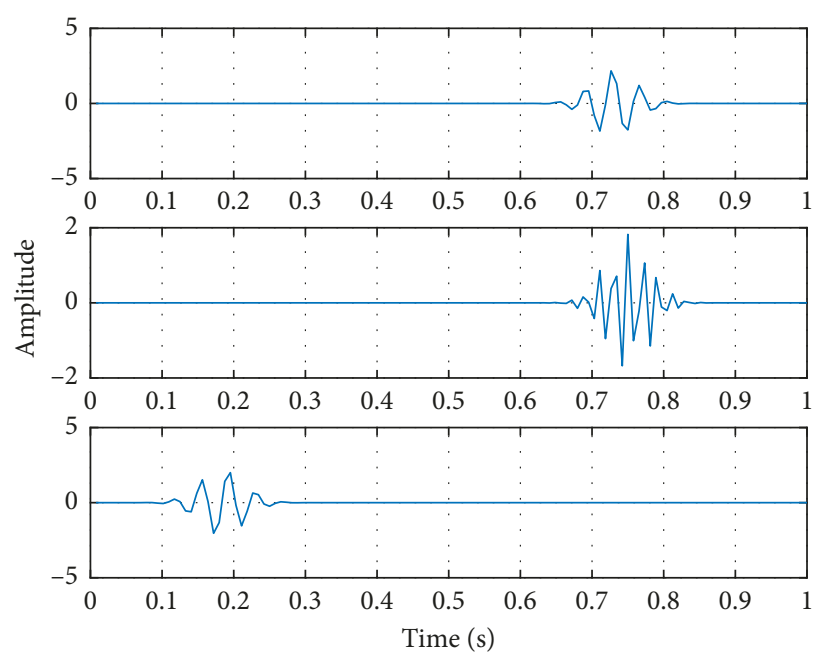

(b)

Figure 2: Synthetic sample signal. (a) Synthetic signal. (b) Components.

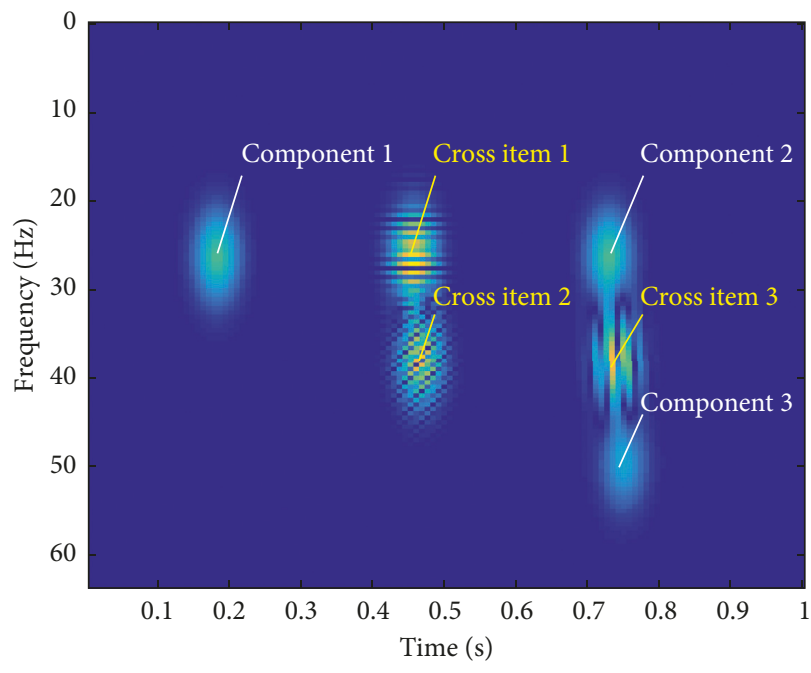

(a)

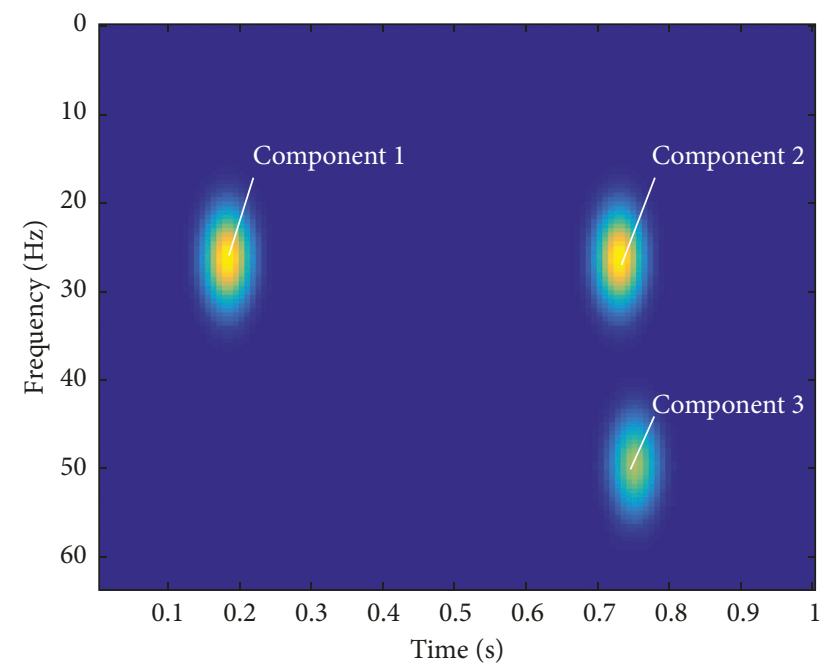

(b)

FIgURE 3: Comparison of the algorithms. (a) WVD time-frequency distribution. (b) WVD time-frequency distribution after subwave decomposition.

frequency, central time, and phase) scanning operation could be reduced to 2 parameters (amplitude and central time) scanning, which greatly reduced the number of steps of the program. The program flow is shown in the Figure 4.

The efficiency of the conventional MP algorithm and the improved MP algorithm were compared.

It could be seen from the comparative analysis of Table 1 that the efficiency of the algorithm had been significantly improved. The time used to deal with the same signal has been reduced by about 40 times.

\section{X80-OD 1422 mm-13.3 MPa Pipeline Explosion Experiment}

4.1. Introduction of the Experiment. The experiment selected the Chinese third-generation natural gas pipeline [18]. The diameter of the pipe was $1422 \mathrm{~mm}$, and the material was X80 pipeline steel. This specification pipeline has been widely used in the West-East Gas Pipeline Project. The parameters are shown in Table 2. The pipeline was filled with natural gas; inner pressure was $13.3 \mathrm{MPa}$, and the gas composition is shown in Table 3.

The total length of the experimental pipeline was $430 \mathrm{~m}$. It consisted of two sections. The length of the gas storage part at both ends was $150 \mathrm{~m}$, and the length of the experimental part in the middle of the pipeline was $130 \mathrm{~m}$. The experimental site is shown in Figure 5. The gas storage parts were buried first. After the preparation was finished, the experimental part was also buried [19].

In this experiment, taking the initiation point as the coordinate origin, the measurement lines were set in two directions. On the vertical line, there were measurement points $1 \# \sim 10 \#$. On the parallel line, there were measurement points $11 \# \sim 20 \#$. At each measurement point, a vibration 


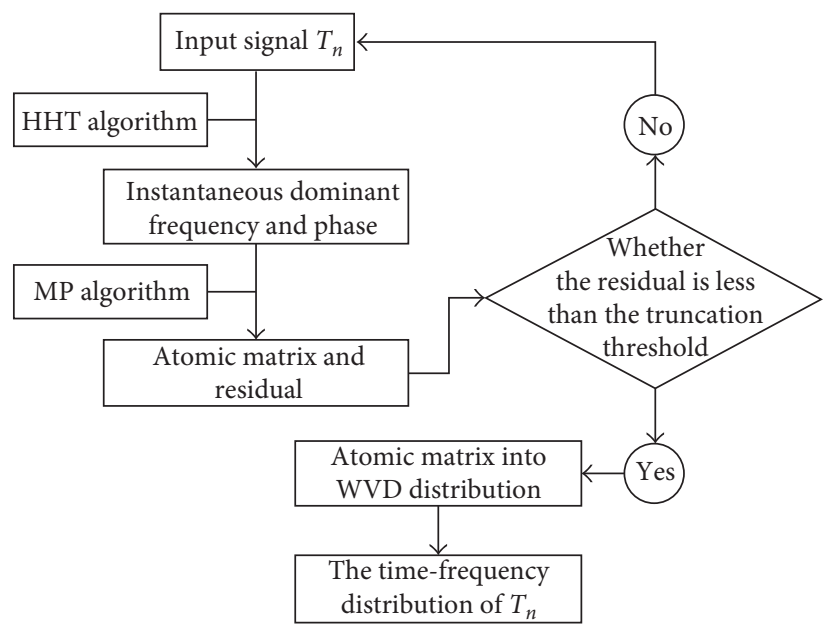

Figure 4: The program flow.

TABLe 1: CPU time comparison of the two methods.

\begin{tabular}{|c|c|c|c|}
\hline Synthetic signal type & Signal waveform & $\begin{array}{c}\text { The time spent by traditional MP } \\
\text { algorithms (s) }\end{array}$ & $\begin{array}{c}\text { The time spent by improved MP } \\
\text { algorithms (s) }\end{array}$ \\
\hline Gauss signal & & 76.15 & 1.76 \\
\hline Triple sine & & 81.93 & 1.68 \\
\hline $\begin{array}{l}\text { Typical blasting vibration } \\
\text { signal }\end{array}$ & & 80.18 & 1.61 \\
\hline
\end{tabular}

TABLe 2: Parameters of the experimental pipeline.

\begin{tabular}{lccccccc}
\hline $\begin{array}{l}\text { Piping } \\
\text { material }\end{array}$ & Diameter $(\mathrm{mm})$ & $\begin{array}{c}\text { Modulus of } \\
\text { elasticity }(\mathrm{GPa})\end{array}$ & $\begin{array}{c}\text { Poisson's } \\
\text { ratio }\end{array}$ & $\begin{array}{c}\text { Yield strength } \\
(\mathrm{MPa})\end{array}$ & $\begin{array}{c}\text { Wall thickness } \\
(\mathrm{mm})\end{array}$ & $\begin{array}{c}\text { Buried depth } \\
(\mathrm{m})\end{array}$ & $\begin{array}{c}\text { Pressure } \\
(\mathrm{MPa})\end{array}$ \\
\hline $\mathrm{X} 80$ & 1422 & 206 & 0.3 & 578 & 22.4 & $1.2 \sim 1.3$ \\
\hline
\end{tabular}

TABle 3: Composition of the experimental gas.

\begin{tabular}{lcccrr}
\hline Component & $\mathrm{CH}_{4}$ & $\mathrm{CH}_{3} \mathrm{CH}_{3}$ & $\mathrm{CO}_{2}$ & $\mathrm{~N}_{2}$ & Others \\
\hline Mol\% & 94.91 & 2.55 & 0.94 & 1.4 & 0.2 \\
\hline
\end{tabular}

velocity sensor and a vibration acceleration sensor were placed. The distribution of the measurement points is shown in Figure 6.

The vibration recorders used in the experiment were type TC-4850 and type Blast-UM. They were all equipped with three-vector sensors, which could record three mutually perpendicular vibrations ( $X$-axis, $Y$-axis, and $Z$ axis). When the sensor was installed, the $X$-axis pointed to the initiation point. Technical parameters are shown in Table 4. In this experiment, the trigger threshold was set to $0.1 \mathrm{~cm} / \mathrm{s}$ (velocity recorders) and $0.1 \mathrm{~g}$ (acceleration recorders), the sampling frequency was set to 10000 Sps, and the acquisition time was set to $10 \mathrm{~s}$.

The explosion process is shown in the Figure 7. The maximum diameter of the fireball was about $150 \mathrm{~m}$, and the height of the mushroom cloud was about $300 \mathrm{~m}$. The 


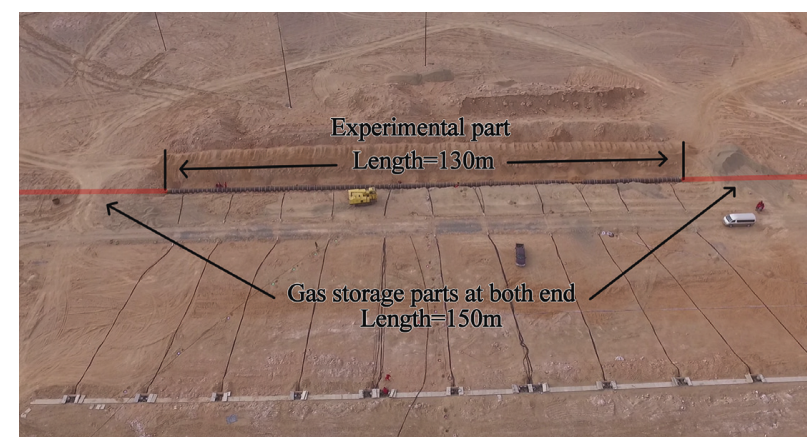

FIGURE 5: Aerial photograph of experimental site.

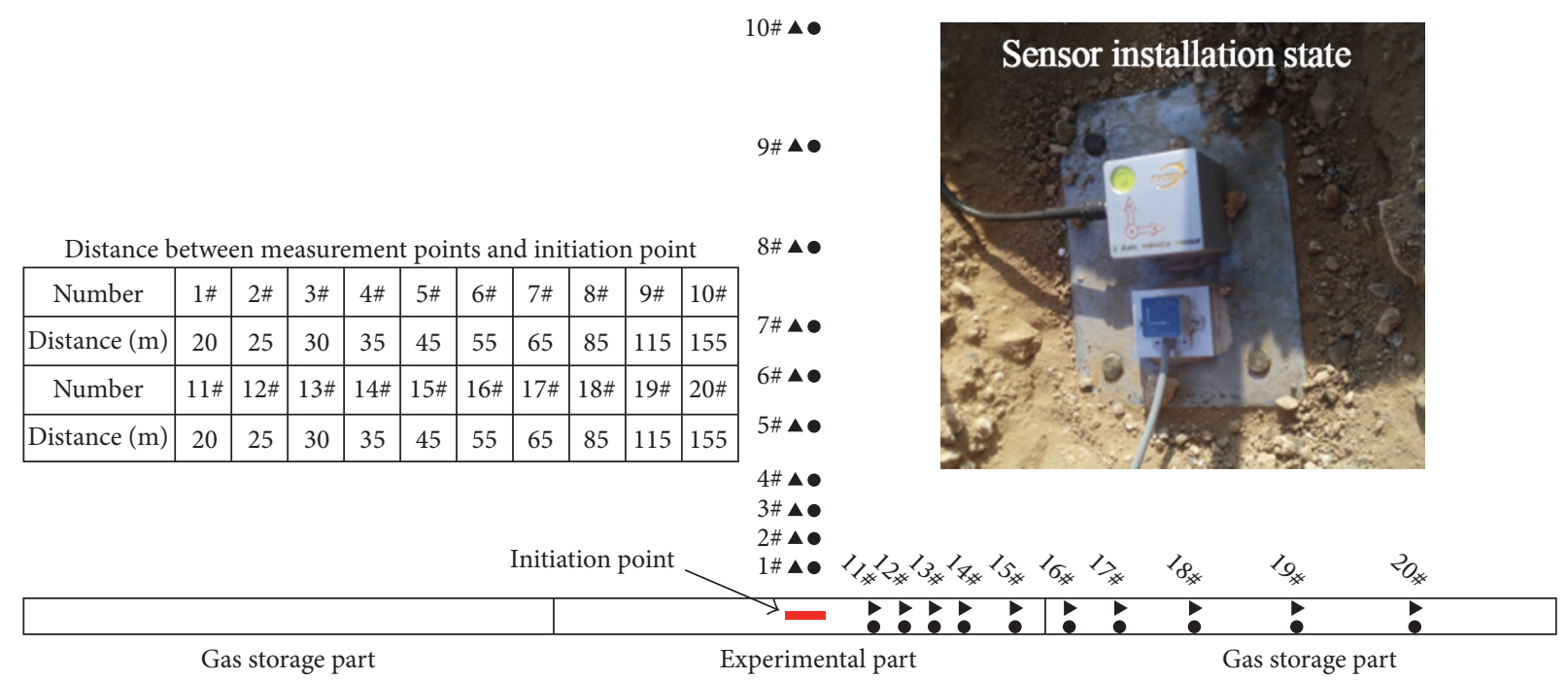

- Vibration velocity sensor

- Vibration acceleration sensor

FIGURE 6: Layout scheme of measurement point.

TABLE 4: Technical parameters of the vibration recorders.

\begin{tabular}{lcccccc}
\hline Type & Number of the channels & Frequency range $(\mathrm{Hz})$ & Range $(\mathrm{cm} / \mathrm{s})$ & Resolution $(\mathrm{cm} / \mathrm{s})$ & Reading accuracy & Sampling rate $(\mathrm{Sps})$ \\
\hline Blast-UM & 3 & $5 \sim 300$ & $<35$ & 0.01 & $0.1 \%$ & $1 \mathrm{~K} \sim 10 \mathrm{~K}$ \\
TC-4850 & 3 & $5 \sim 500$ & $<35$ & 0.01 & $0.1 \%$ & $1 \mathrm{~K} \sim 50 \mathrm{~K}$ \\
\hline
\end{tabular}

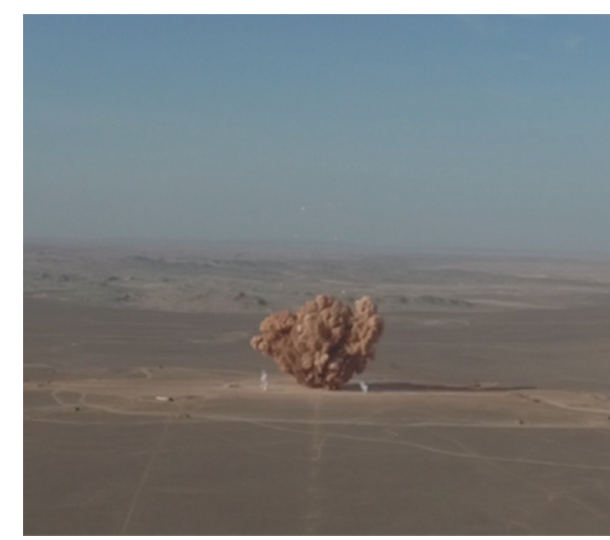

(a)

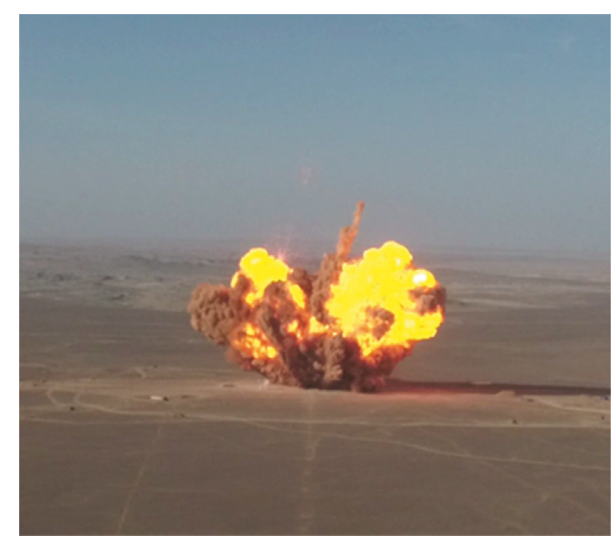

(b)

Figure 7: Continued. 


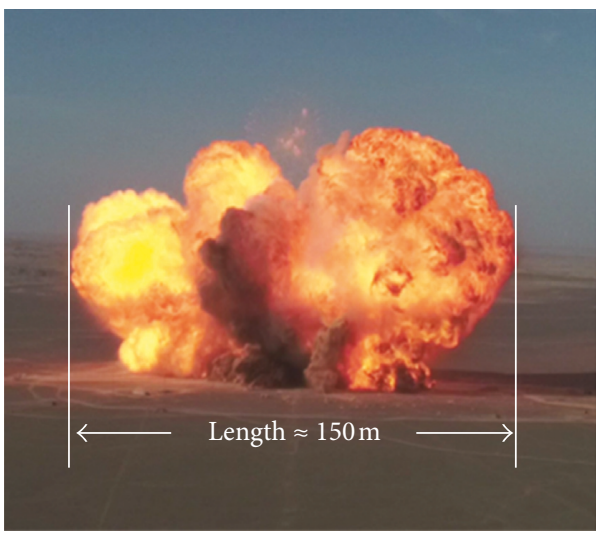

(c)

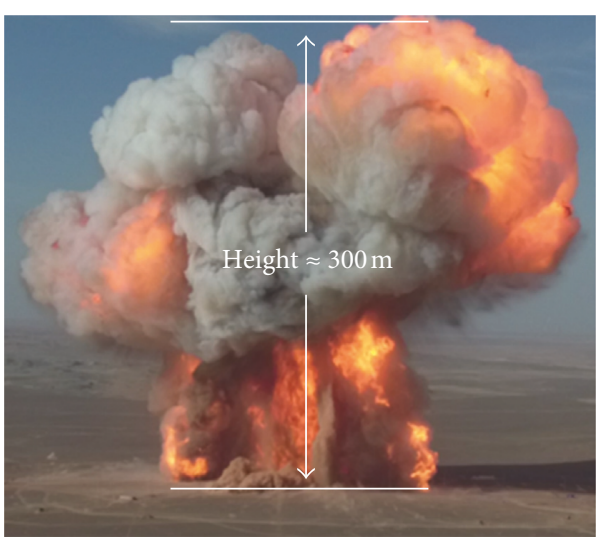

(d)

FIgURE 7: Explosion scene.

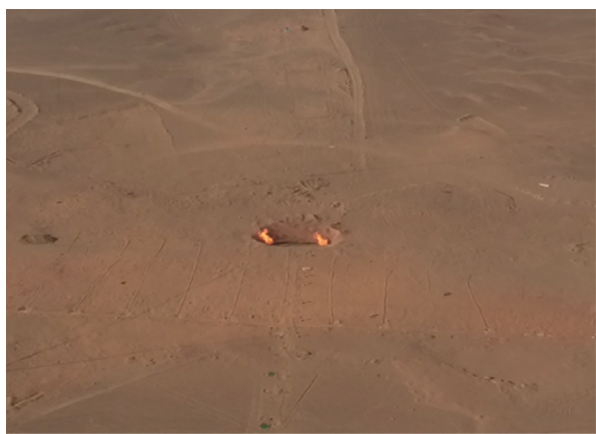

(a)

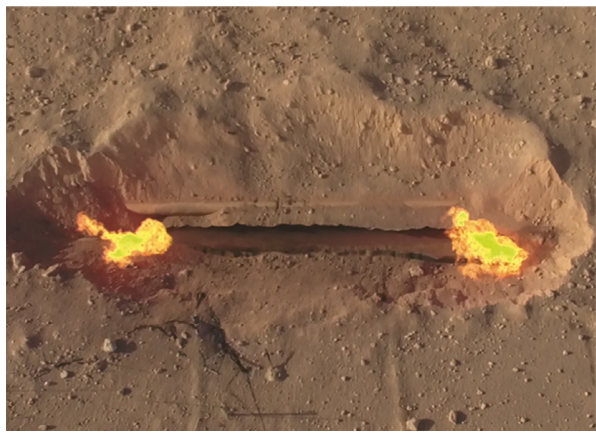

(c)

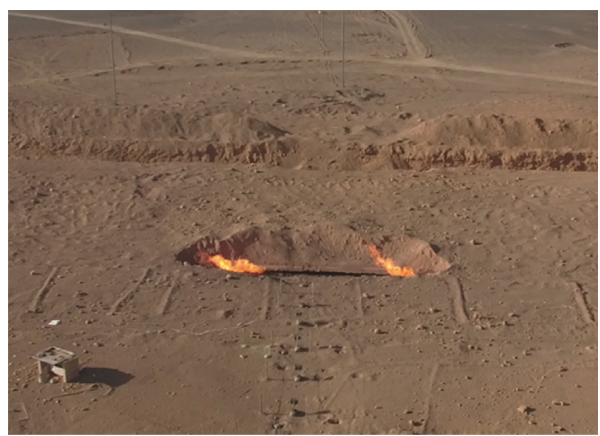

(b)

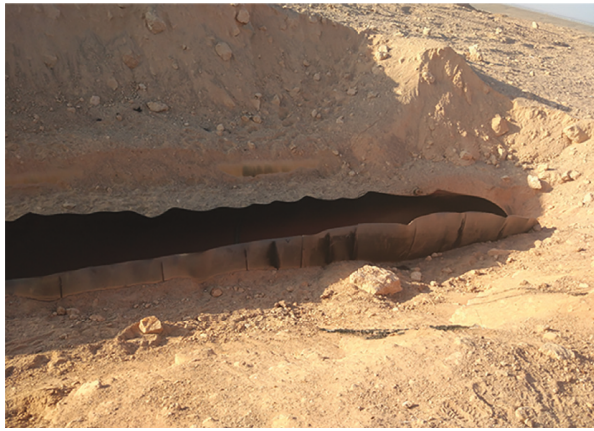

(d)

FIGURE 8: Crack in pipeline.

observation station was 2 kilometers away from the center of the detonation, and the observers could obviously feel the heat radiation. At the first moment after the explosion, UAVs were sent to conduct investigations on the explosion site. It could be seen that the pipe crack was about $20 \mathrm{~m}$ long, and there were still residual flames, as shown in the Figure 8.

4.2. Data Processing. Taking the vertical component ( $Z$-axis) data of measuring point $1 \#$ as an example, the improved MPWVD algorithm was used to analyze. The first step was MP decomposition [20].
As could be seen from Figure 9, the decomposed subwave had good compactness and could show the details of the signal accurately. At the same time, it was found that the MP algorithm had an excellent high-frequency dryness effect for blasting vibration signal [21]. Compared with other filtering algorithms, the results are shown in Table 5 .

As could be seen from the table, the reconstruction signal obtained by the MP algorithm preserved almost all the details of the original signal [22]. At the same time, noise was eliminated. However, the result of traditional low-pass filtering had a serious phase difference compared with the original signal. Therefore, the time information of the signal was changed. Due to the adaptive basement algorithm, the 


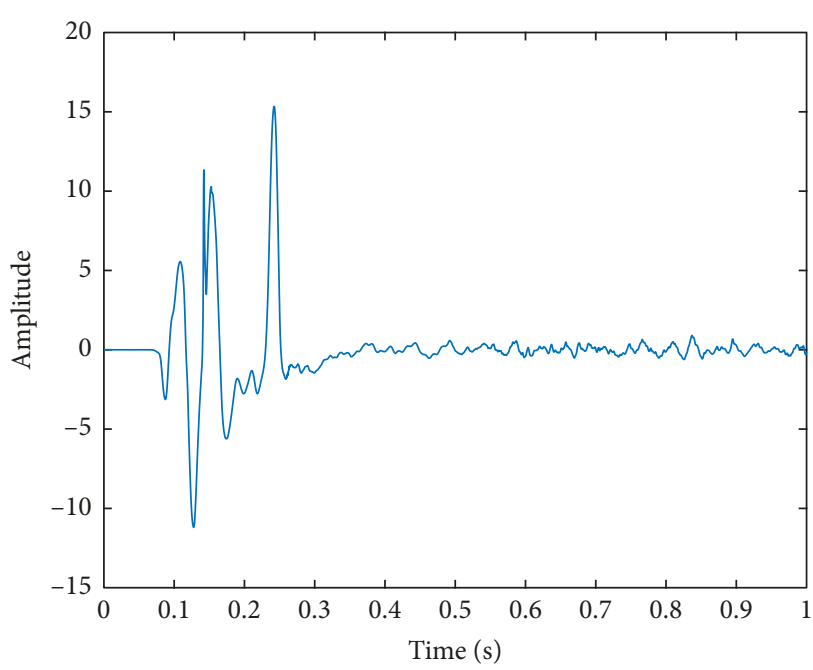

(a)

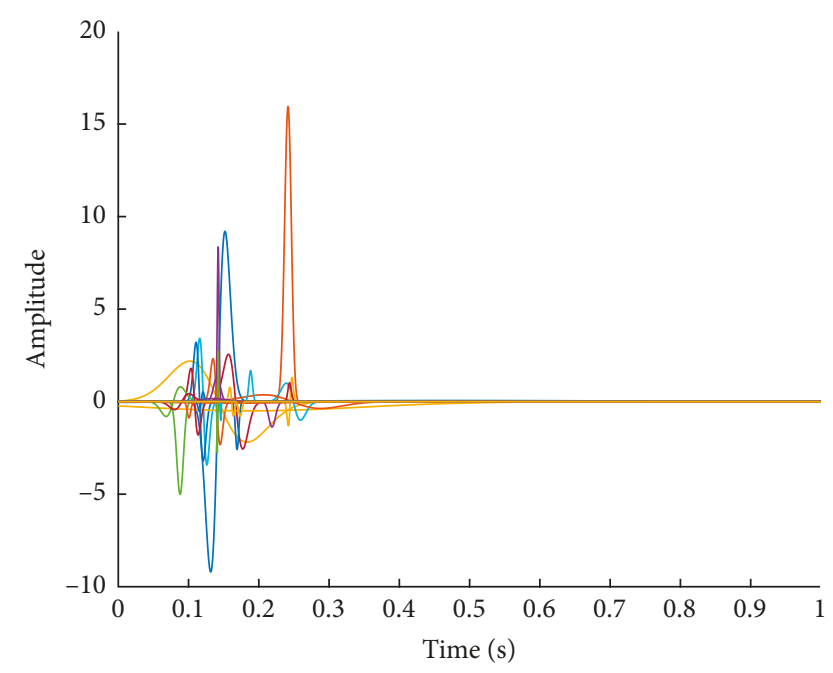

(b)

FIgURE 9: Data of measuring point 1\#. (a) Original signal. (b) Subwave set.

TABle 5: Contrast of filtering effect.

Filtering method

MP algorithm filtering

Low-pass filtering

EMD filtering

\section{Filtering effect}

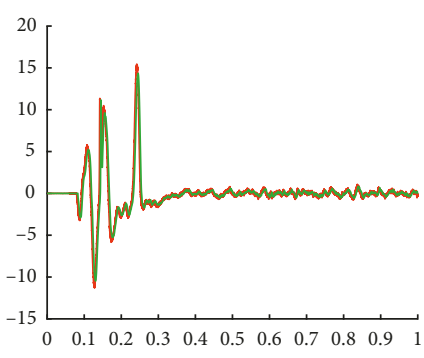

— Original signal

_ Reconstruction signal

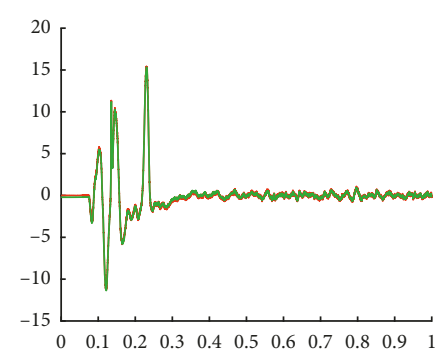

- Original signal

__ Reconstruction signal

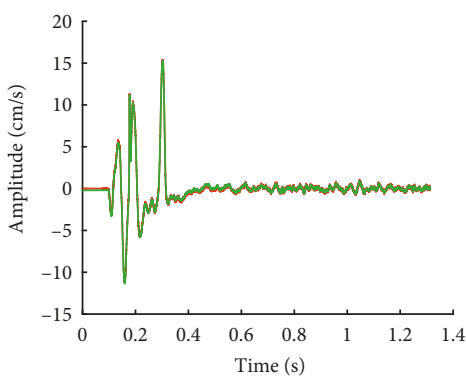

Original signal

Reconstruction signal
Detail Residual
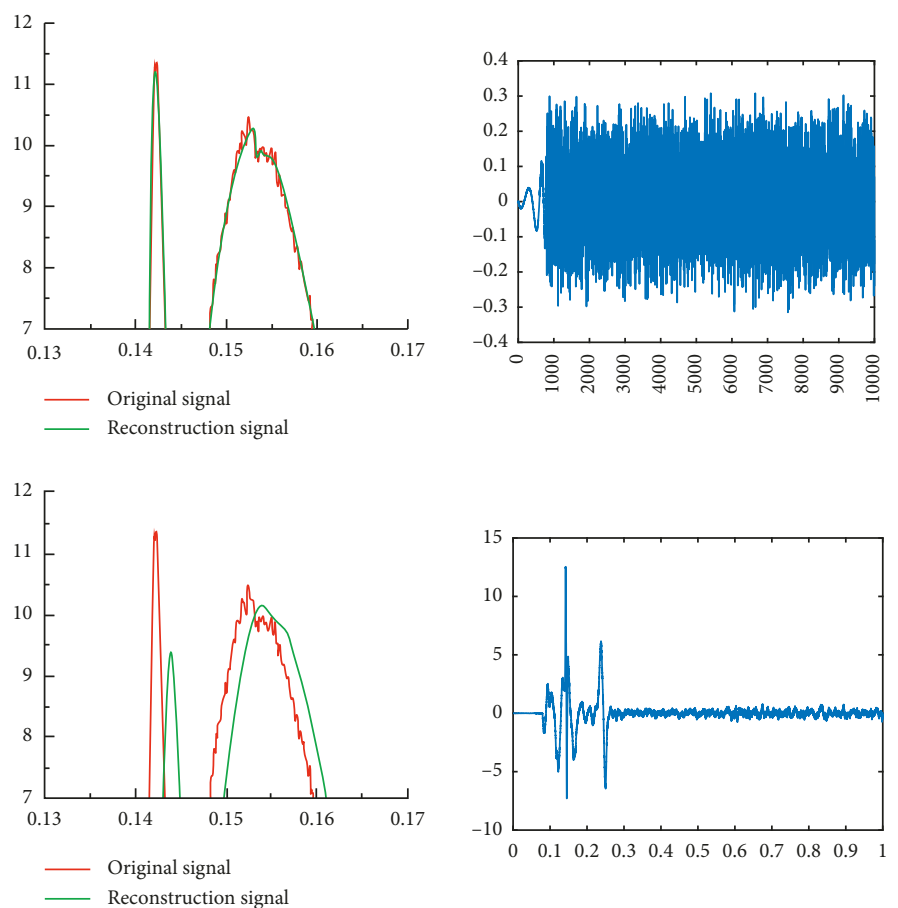

_ Reconstruction signal
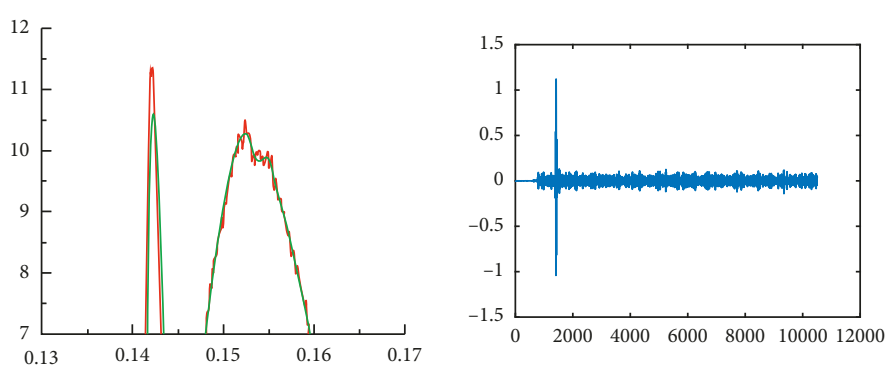

— Original signal

__ Reconstruction signal 


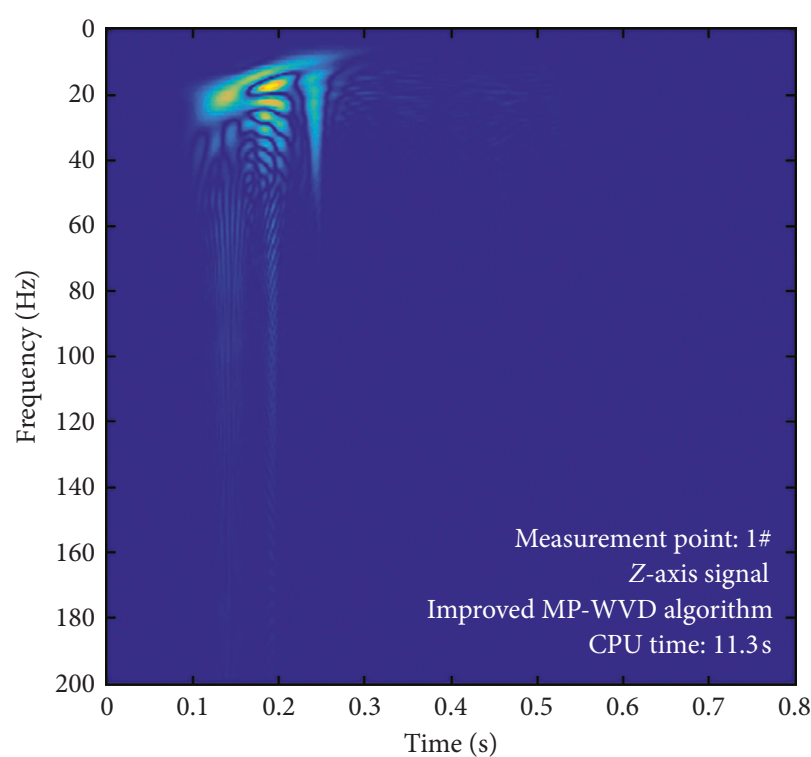

(a)

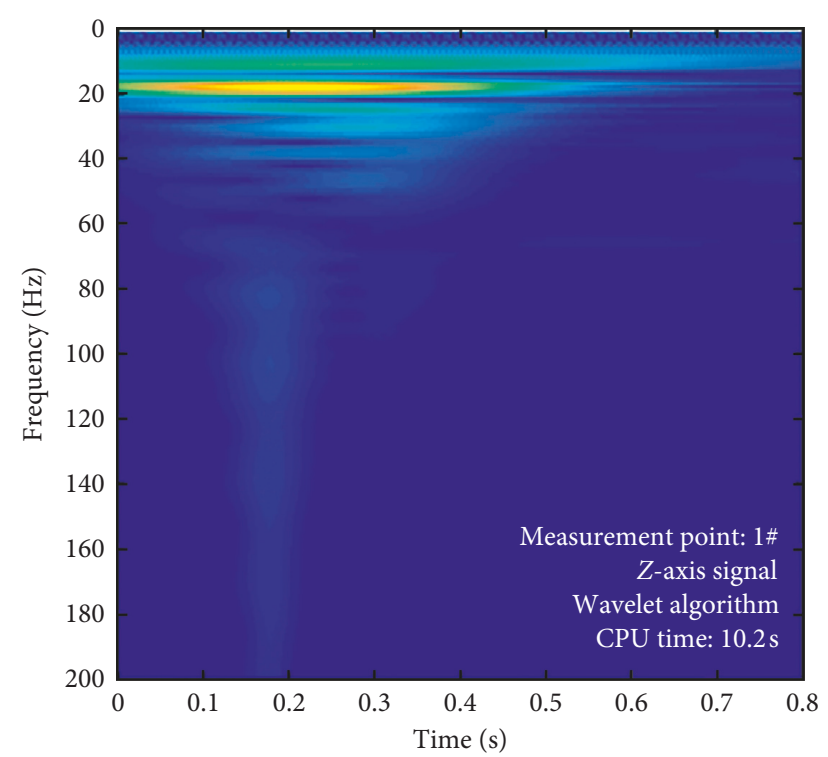

(b)

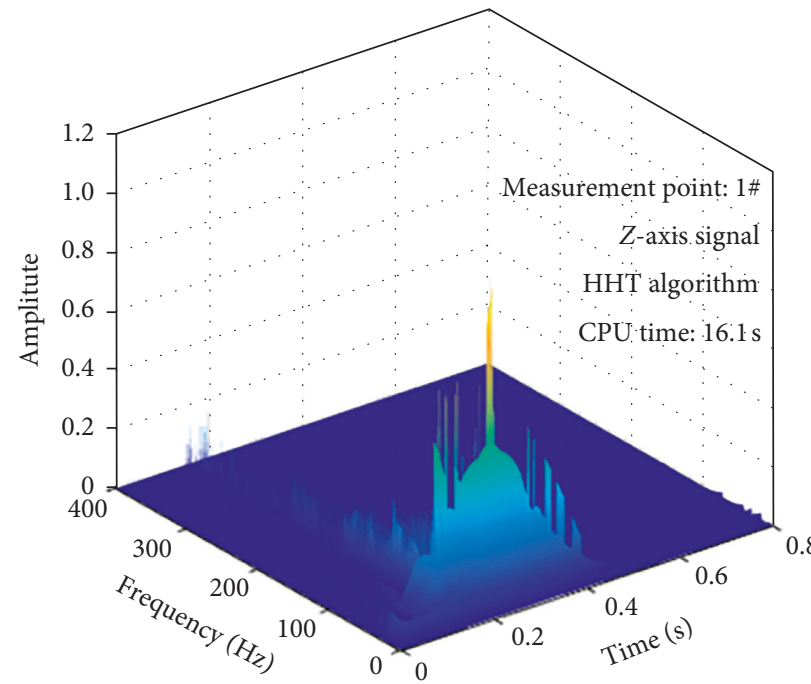

(c)

FIgURE 10: The time-frequency distribution of 1\# (Z-axis). (a) Improved MP-WVD. (b) Wavelet. (c) HHT.

EMD algorithm was very fast, but the filtering effect was not stable. So it was easy to remove the useful information together [23-25]. On the other hand, the boundary effect also introduced interference signals. As shown in the table, the difference between the reconstructed signal and the original signal was large.

The obtained atomic matrix was brought into the WVD algorithm and calculated the time-frequency distribution of each atom, respectively, and added them up. The overall time-frequency distribution of the signal was obtained, and the results of the wavelet transform and HHT were compared, as shown in the Figure 10.

It could be seen from the figure that both the time resolution and frequency resolution of the wavelet transform were not as good as the MP-WVD algorithm. At the same time, there was some boundary overflow. The time spectrum obtained by the HHT algorithm had a very obvious boundary effect. There was a fairly strong energy distribution in the VLF part, which was not consistent with the fact. The MP-WVD algorithm not only had a high-frequency resolution, but also described the frequency distribution of the wave with time.

The characteristics of the vibration signal could be identified clearly from the figure. In the time range of $0.1 \sim 0.15 \mathrm{~s}$, there was the first group of waves in the time-frequency domain. Its main energy was distributed around $20 \mathrm{~Hz}$. The frequency range was relatively concentrated. In the time range of $0.18 \mathrm{~s} \sim 0.22 \mathrm{~s}$, there was the second group of waves. Their energy was mainly concentrated in the range of $10 \sim 50 \mathrm{~Hz}$, and the amplitude was larger than that of the first group. In the time range of $0.23 \sim 0.27 \mathrm{~s}$, the third peak appeared. The 


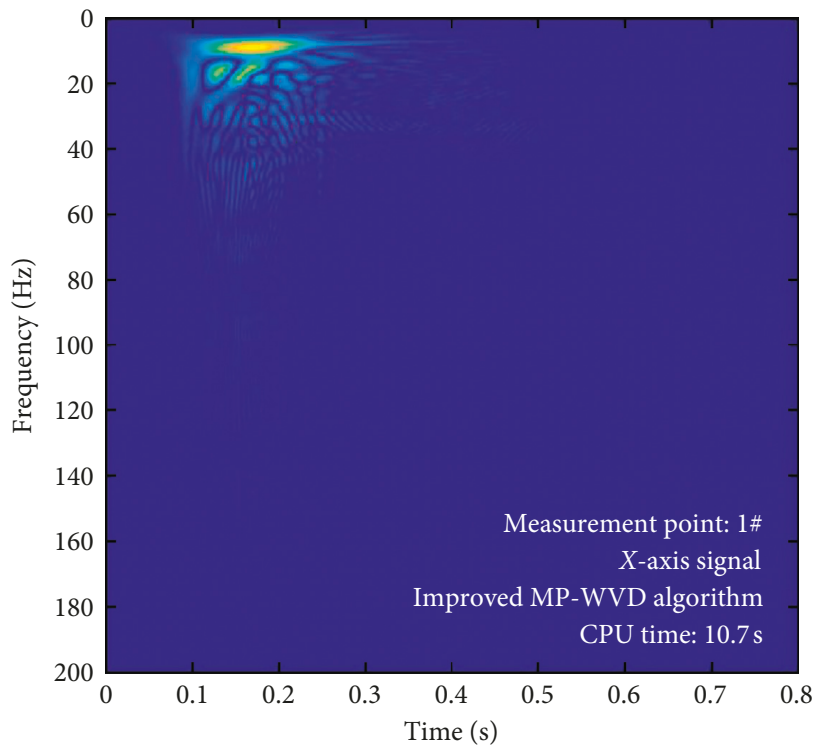

(a)

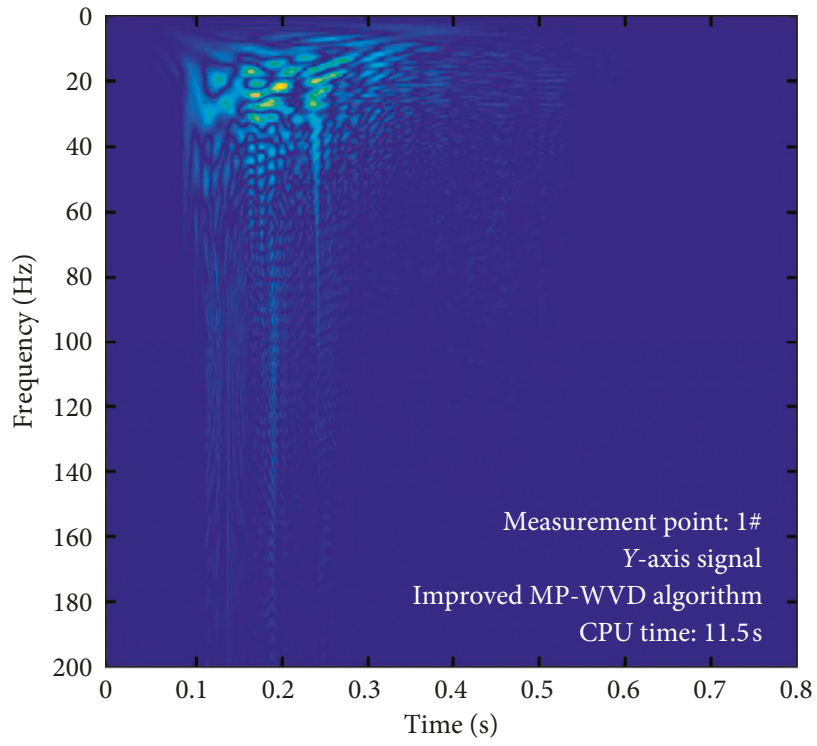

(b)

FIgURE 11: WVD distribution of $1 \#$. (a) Horizontal radial ( $X$-axis). (b) Horizontal tangential ( $Y$-axis).

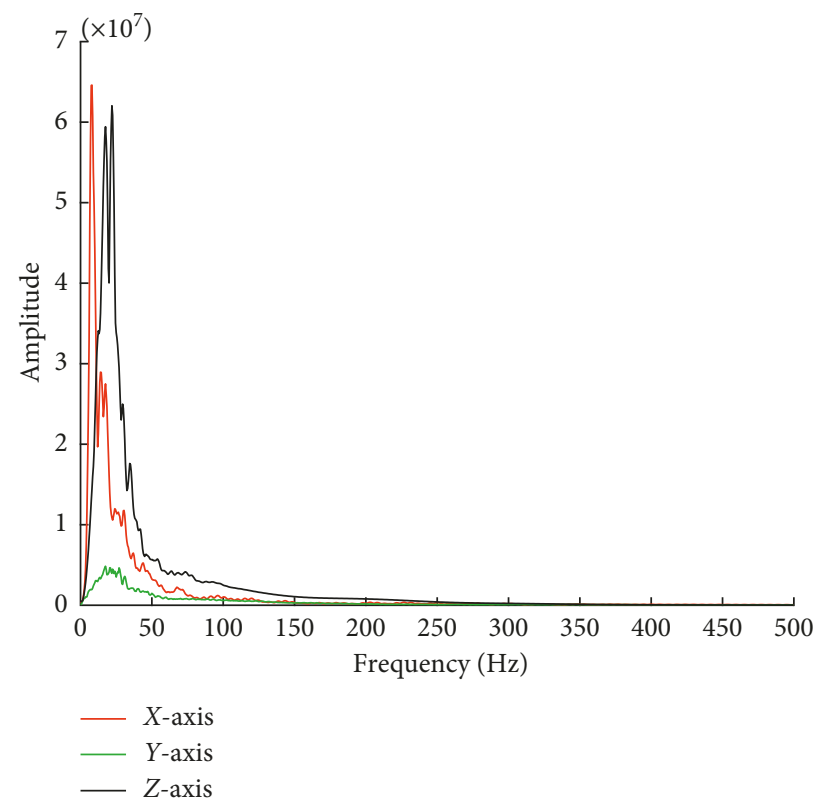

FIgURE 12: The marginal spectrum of $1 \#$.

frequency of this group mainly concentrated in the range of $5 \sim 50 \mathrm{~Hz}$. Its amplitude was smaller than the first two.

Further, taking the horizontal radial signal ( $X$-axis) and the horizontal tangential signal ( $Y$-axis) into the algorithm, the time-frequency distribution was obtained, as shown in Figure 11.

The time-frequency distribution characteristics of the vibration in three directions were compared. Their similarities and differences were obtained: The vibration energy of the $X$-axis was mainly around $8 \mathrm{~Hz}$, and the duration of the vibration was about $0.15 \mathrm{~s}$. Its energy distribution was more concentrated. In comparison, the energy of the horizontal tangential distribution was more dispersed in the time-frequency domain. Its duration of the vibration was about $0.25 \mathrm{~s}$. The main energy was distributed in the frequency range of $0 \sim 40 \mathrm{~Hz}$.

Further, the time integral and frequency integral of the WVD distribution were carried out, and the marginal spectrum and the instantaneous energy spectrum were obtained.

As shown in the Figure 12, the marginal spectrum described the accumulation of the frequency spectrum in the time domain, and its result was in general agreement with the WVD distribution. The difference was that it was more accurate to see the $Z$-axis signal accumulated more at the $17.5 \mathrm{~Hz}$ and $22 \mathrm{~Hz}$ in the marginal spectrum. The 


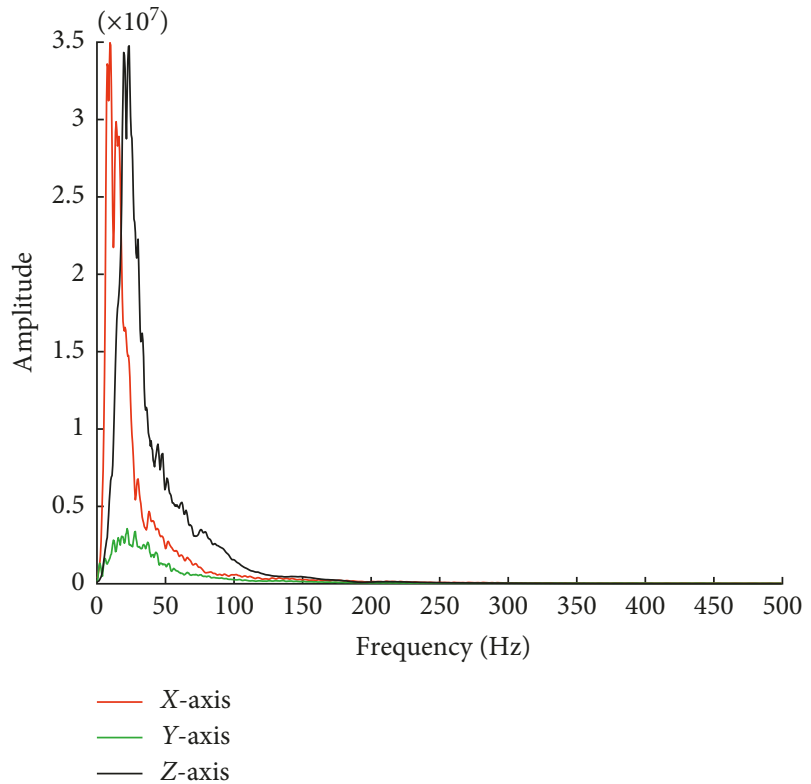

(a)

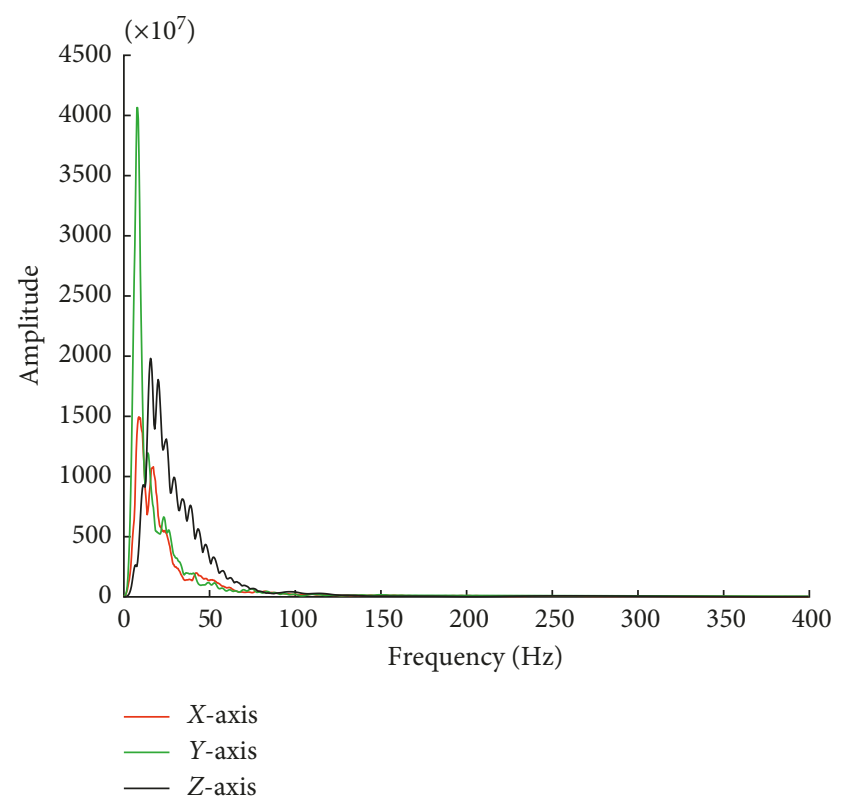

(c)

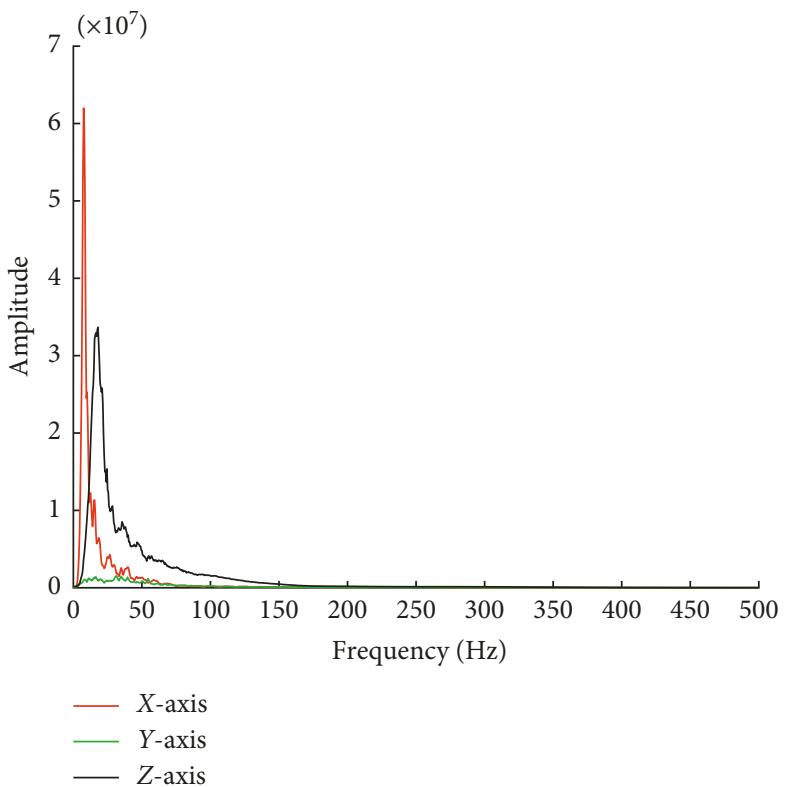

(b)

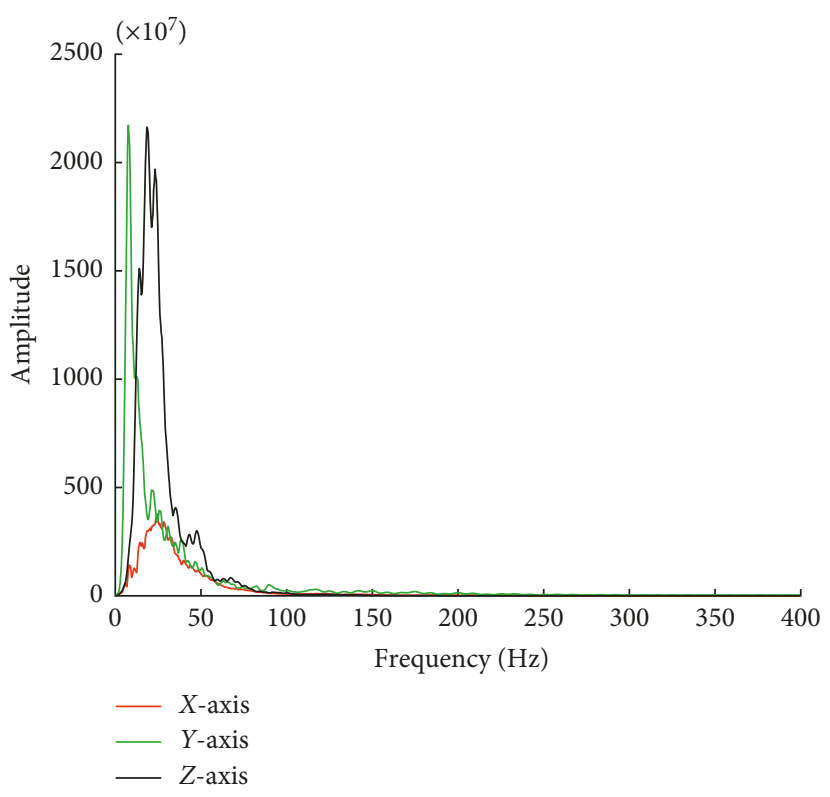

(d)

Figure 13: The marginal spectrum of $2 \#, 3 \#, 13 \#$, and $14 \#$.

data of several measurement points were processed, and the results are shown in Figure 13. The following conclusions could be obtained by comparing the results of several groups. (1) The energy of the pipeline explosion vibration wave was mainly distributed between 0 and $40 \mathrm{~Hz}$. (2) On the vertical measurement line, the frequency center of the $Z$-axis and $Y$-axis was about $20 \mathrm{~Hz}$, and that of the $X$-axis was about $10 \mathrm{~Hz}$. (3) On the parallel measurement line, the frequency center of the $Z$-axis was about $20 \mathrm{~Hz}$, and that of the $Y$-axis was about $10 \mathrm{~Hz}$. The frequency center of the $X$-axis was uncertain.

In Figure 14, it could be clearly seen that the vibration energy has three stages of loading. Compared with Figure 15, the same conclusion could still be obtained. The difference was that the vibration intensity of the $Y$-axis on the parallel measurement line was obviously higher than that on the vertical measurement line. It could be seen from the figures that the vibration mode of natural gas pipeline explosion differed in different directions.

Through the analysis above, some conclusions could be obtained. Since the $X$-axes of all the sensors pointed to the initiation point, the $X$-axis of the sensors on the vertical line and the $Y$-axis of the sensors on the horizontal line were all perpendicular to the direction of the pipeline axis. That is to say, the horizontal vibration caused by pipeline explosion was mainly perpendicular to 


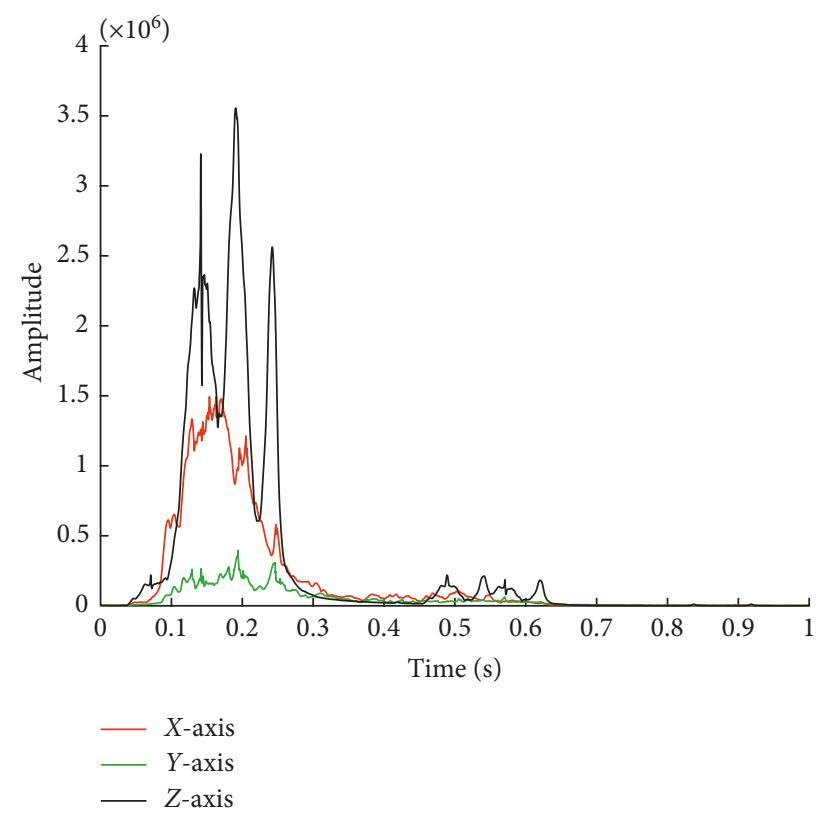

FIgURE 14: The instantaneous energy spectrum of $1 \#$.
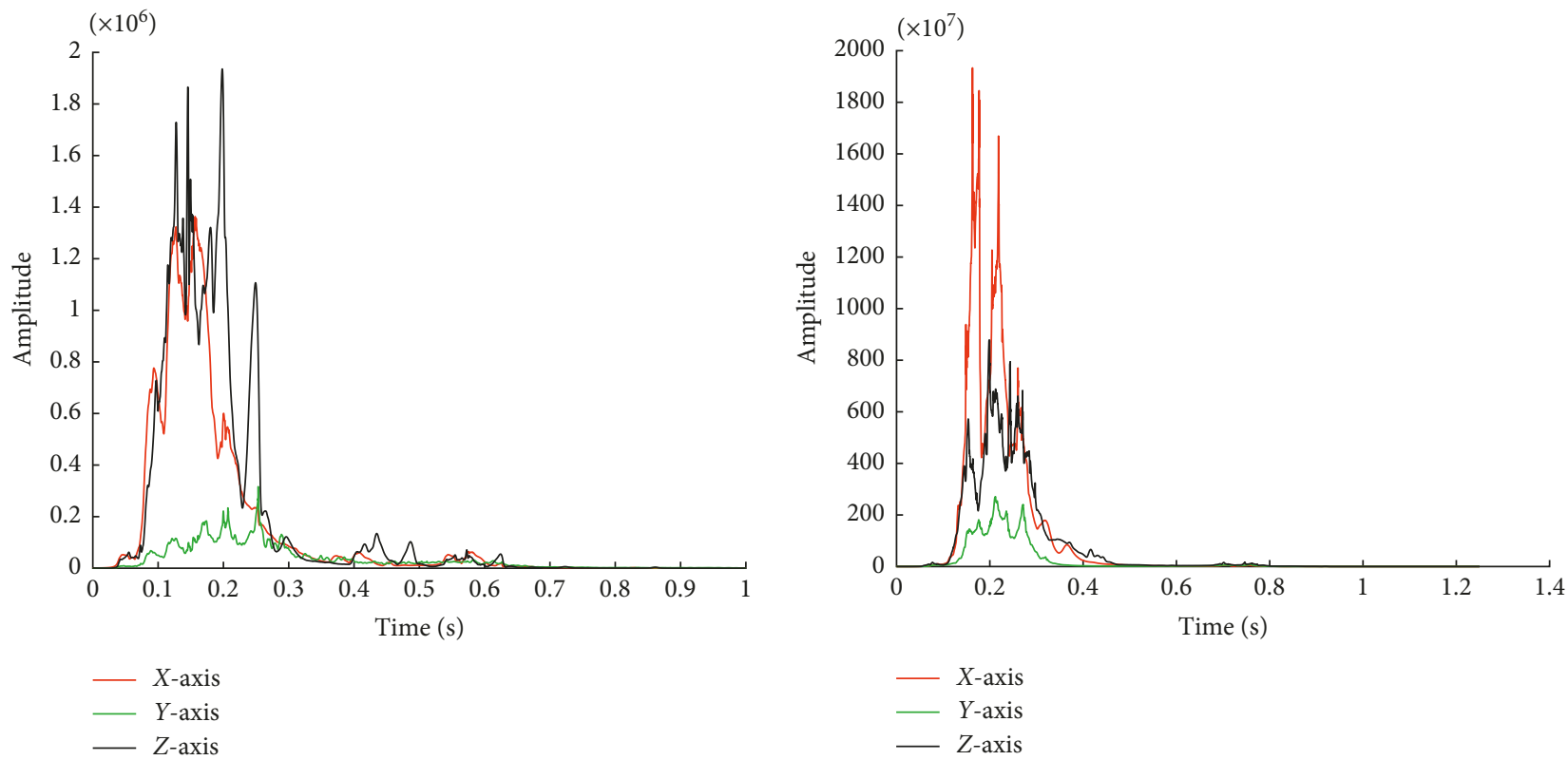

(a)

(b)

Figure 15: Continued. 


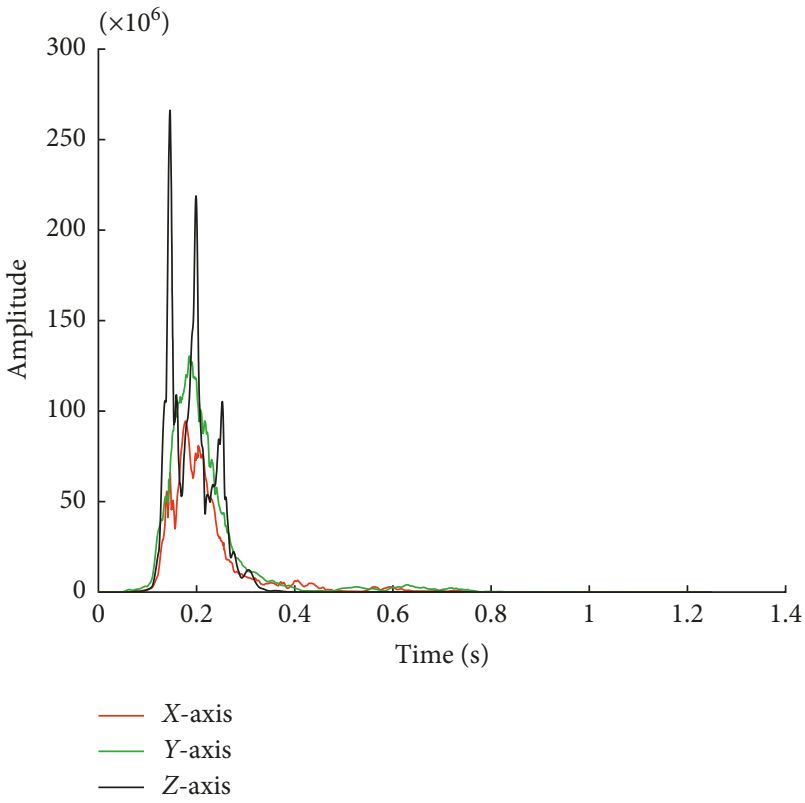

(c)

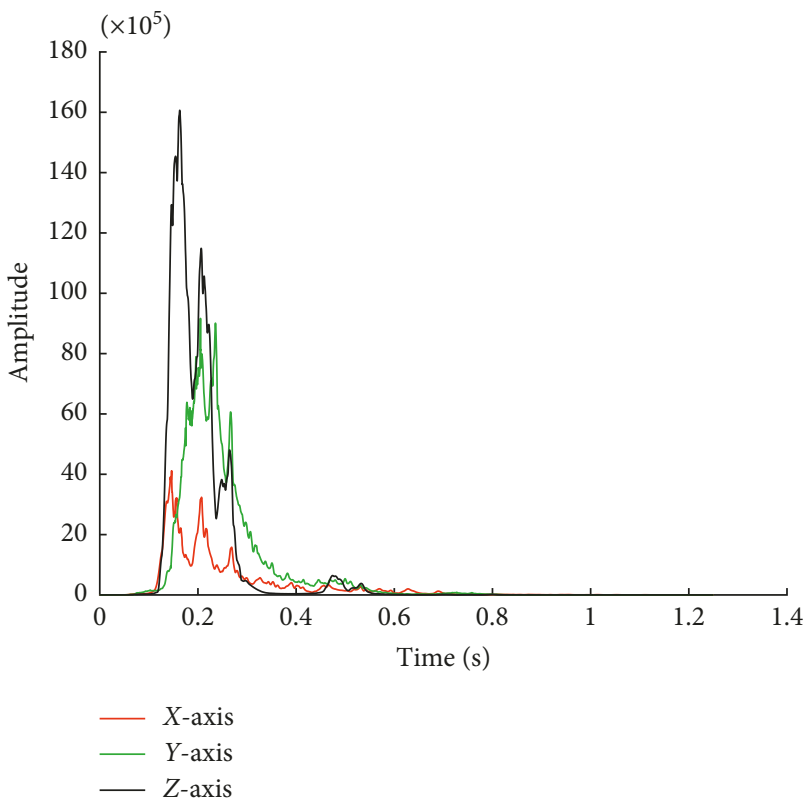

(d)

Figure 15: The instantaneous energy spectrum.

the pipeline direction. Therefore, the buildings around the pipeline need to strengthen the aseismic strength perpendicular to the pipe direction. From the point of view of vibration frequency, when engineers conduct pipeline safety design, special attention must be paid to the range of $0 \sim 40 \mathrm{~Hz}$. The natural frequencies of buildings around pipelines, such as pressurized stations or parallel pipelines, should avoid this range of frequencies, especially around $10 \mathrm{~Hz}$ and $20 \mathrm{~Hz}$.

\section{Discussion}

(1) The combination of HHT, MP, and WVD algorithm has achieved good results in signal analysis. It not only solved the problem of cross terms, but also showed high computing efficiency. At the same time, it was found that the improved MP algorithm had a good denoising effect. Compared with low-pass filtering and EMD filtering, it behaved more efficiently and accurately. This research provided a new algorithm for the time-frequency distribution of nonstationary random vibration.

(2) The vibration energy of the natural gas pipeline explosion was mainly distributed in the frequency range of $0 \sim 40 \mathrm{~Hz}$, and the duration was $0.1 \sim 0.25 \mathrm{~s}$. The natural frequencies of buildings around pipelines should avoid this range of frequencies, especially around $10 \mathrm{~Hz}$ and $20 \mathrm{~Hz}$. The pipeline explosion vibration had three stages of loading, and the vibration mode differed in different directions. The horizontal vibration caused by pipeline explosion was mainly perpendicular to the pipeline direction. So it was suggest that the buildings around the pipeline strengthen the aseismic strength perpendicular to the pipe direction.

(3) Since the characteristics of the vibration generated by the explosion are related to the source of explosion and the soil medium, the results obtained in this experiment were applicable to the X80-OD $1422 \mathrm{~mm}$ pipeline and buried in the Gobi soil similar to the test site. At present, in the West-East Gas Pipeline Project, a considerable length of pipeline meets this applicable condition. For other specifications of pipelines or other soil media, there is still a lot of work needed to be supplemented by scholars.

\section{Data Availability}

The data used in this article can be obtained in the following links. https://figshare.com/s/e2aea8d0ff64d0fcebed. As the data laws continue to be studied, the data at other measurement points are not supported for download.

\section{Conflicts of Interest}

The authors declare that they have no conflicts of interest.

\section{Acknowledgments}

This research was supported by the National Natural Science Foundation of China (nos. 11672331 and 51608530). The authors would like to gratefully acknowledge this support. 


\section{References}

[1] S. Yang, Q. Fang, Y. Zhang, H. Wu, and L. Ma, "An integrated quantitative hazard analysis method for natural gas jet release from underground gas storage caverns in salt rock. I: models and validation," Journal of Loss Prevention in the Process Industries, vol. 26, no. 1, pp. 74-81, 2013.

[2] B. N. Leis, X. K. Zhu, and T. P. Forte, "New approach to assess running fracture arrest in pipelines," in Proceedings of the Pipeline Technology Conference, pp. 12-14, Ostend, Belgium, October 2009.

[3] B. J. Lowesmith and G. Hankinson, "Large scale experiments to study fires following the rupture of high pressure pipelines conveying natural gas and natural gas/hydrogen mixtures," Process Safety and Environmental Protection, vol. 91, no. 1-2, pp. 101-111, 2013.

[4] S. Hua-you, H. Jin, X. Ding-jun, and S. Yan-hua, "Analysis of characteristics of compound vibration and effects to surrounding gas pipeline caused by impact and explosion," Procedia Engineering, vol. 26, pp. 1835-1843, 2011.

[5] K. B. Mishra and K. D. Wehrstedt, "Underground gas pipeline explosion and fire: CFD based assessment of foreseeability," Journal of Natural Gas Science and Engineering, vol. 24, pp. 526-542, 2015.

[6] T. Guo, X. Fang, M. Zhong et al., "Research on the effects of blasting vibration attenuation by pre-split crack with HHT method," Computer Systems Science and Engineering, vol. 31, no. 6, pp. 431-438, 2016.

[7] Z. Yiping, L. Xibing, Z. Guoyan et al., "Time-frequency analysis of blasting vibration signals," Chinese Journal of Geotechnical Engineering, no. 12, pp. 1472-1477, 2005.

[8] L. Da-chao, S. Hui-ji, B. Chun-hua et al., "Time-frequency analysis of explosion seismic effects," Explosion and Shock Waves, no. 1, pp. 31-36, 2003.

[9] A. Majkowski, M. Kołodziej, and R. J. Rak, "Joint timefrequency and wavelet analysis-an introduction," Metrology and Measurement Systems, vol. 21, no. 4, pp. 741-758, 2014.

[10] Z. Guosheng, F. Yingguang, and X. Guoyuan, "Evaluation of blasting vibration effect of building structures based on wavelet transform," Journal of Vibration and Shock, no. 8, pp. 121-182, 2008.

[11] Y. Renshu, G. Xiangtao, C. Yulong et al., "Joint timefrequency analysis of blast strain wave based on HilbertHuang transformation," Journal of Vibration and Shock, vol. 10, no. 33, pp. 17-21, 2014.

[12] M. Thomas, R. Jacob, and B. Lethakumary, "Comparison of WVD based time-frequency distributions," in Proceedings of the International Conference on Power, Signals, Controls and Computation (EPSCICON 2012), pp. 1-8, Thrissur, Kerala, India, January 2012.

[13] L. Zhou, H. Cheng, Z. G. Wang, and S. J. Huang, "Damage identification method for a guyed mast based on WVD crossterm statistic distinction," Journal of Civil Architectural and Environmental Engineering, vol. 31, no. 4, pp. 13-18, 2009.

[14] K. M. M. Prabhu and R. Shanmuga Sundaram, "Some results on fixed-point error analysis of Wigner-Ville distribution," Signal Processing, vol. 51, no. 3, pp. 235-240, 1996.

[15] X. Chen, X. Liu, S. Dong, and J. Liu, "Single-channel bearing vibration signal blind source separation method based on morphological filter and optimal matching pursuit (MP) algorithm," Journal of Vibration and Control, vol. 21, no. 9, pp. 1757-1768, 2015.

[16] P. L. Zhang, H. X. Zhang, L. Y. Huang, and H. Peng-fei, "Multi-parameter identification of power line communication channel model based on matching pursuit," $A E U$ International Journal of Electronics and Communications, vol. 67, no. 8, pp. 697-701, 2013.

[17] W. Yipeng, "Research on matching pursuit based on instantaneous parameters," in Proceedings of the Twenty-Seventh Annual Conference of Chinese Geophysical Society, Chinese Society of Geophysics, vol. 1, Changsha, Hunan, China, October 2011.

[18] S. Sklavounos and F. Rigas, "Estimation of safety distances in the vicinity of fuel gas pipelines," Journal of Loss Prevention in the Process Industries, vol. 19, no. 1, pp. 24-31, 2006.

[19] B. N. Leis, S. M. Pimputkar, and N. D. Ghadiali, Line Rupture and the Spacing of Parallel Lines, American International Pipeline Research Council (PRCI), Chantilly, VA, USA, 2002.

[20] L. Ahmed and A. Ansell, "Structural dynamic and stress wave models for the analysis of shotcrete on rock exposed to blasting," Engineering Structures, vol. 35, pp. 11-17, 2012.

[21] Z. Yan, A. Miyamoto, and Z. Jiang, "Frequency slice algorithm for modal signal separation and damping identification," Computers and Structures, vol. 89, no. 1-2, pp. 14-26, 2011.

[22] S. Xiuzhi, X. Jianguang, and C. Shouru, "Two times timefrequency analysis of bilinear transformation of blasting vibration signal," Journal of Vibration and Shock, vol. 27, no. 12, pp. 131-134, 2008.

[23] Y. Chen, "Dip-separated structural filtering using seislet transform and adaptive empirical mode decomposition based dip filter," Geophysical Journal International, vol. 206, no. 1, pp. 457-469, 2016.

[24] X. Li, Y. Long, C. Ji, M. Zhong, and H. Zhao, "Study on the vibration effect on operation subway induced by blasting of an adjacent cross tunnel and the reducing vibration techniques," Journal of Vibroengineering, vol. 15, no. 3, 2013.

[25] G. Dong, L. Xue, Y. Yang, and J. Yang, "Evaluation of hazard range for the natural gas jet released from a high-pressure pipeline: a computational parametric study," Journal of Loss Prevention in the Process Industries, vol. 23, no. 4, pp. 522530, 2010. 


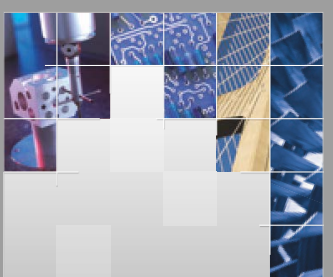

\section{Enfincering}
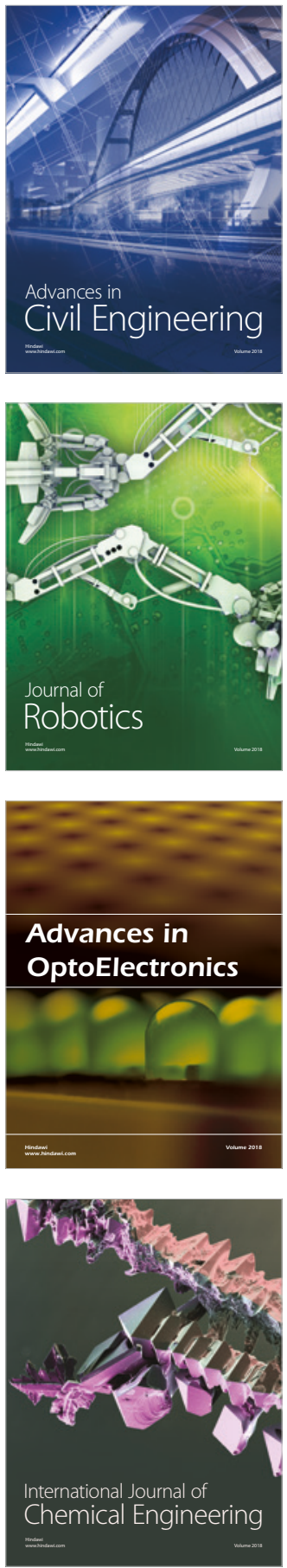

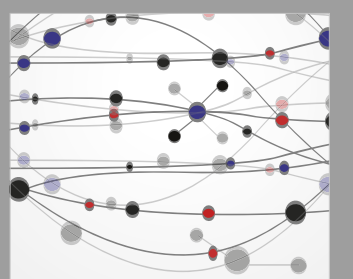

\section{Rotating \\ Machinery}

The Scientific World Journal

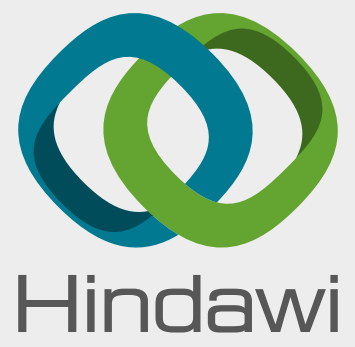

Submit your manuscripts at

www.hindawi.com
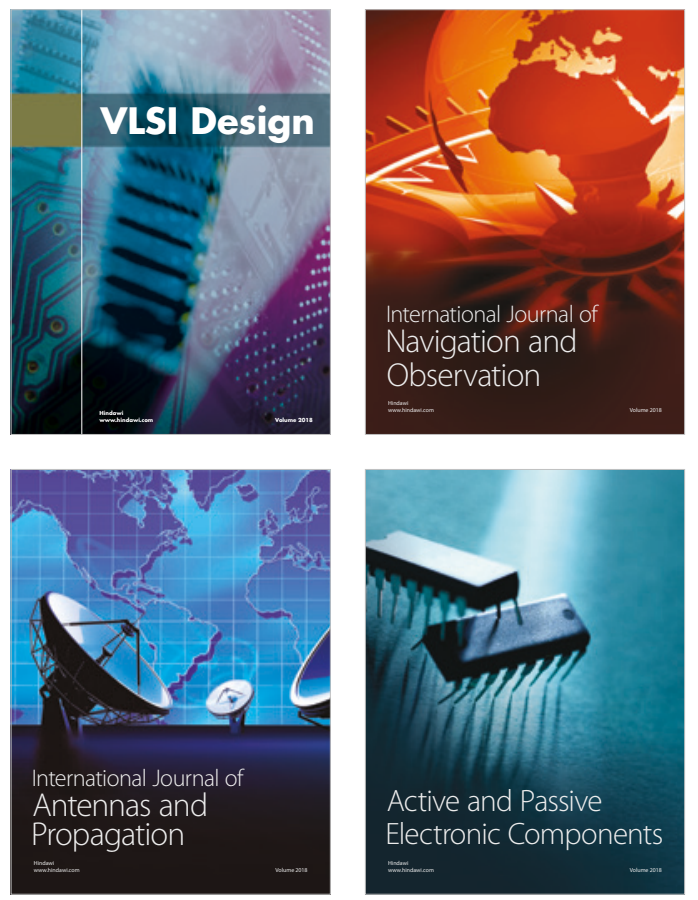
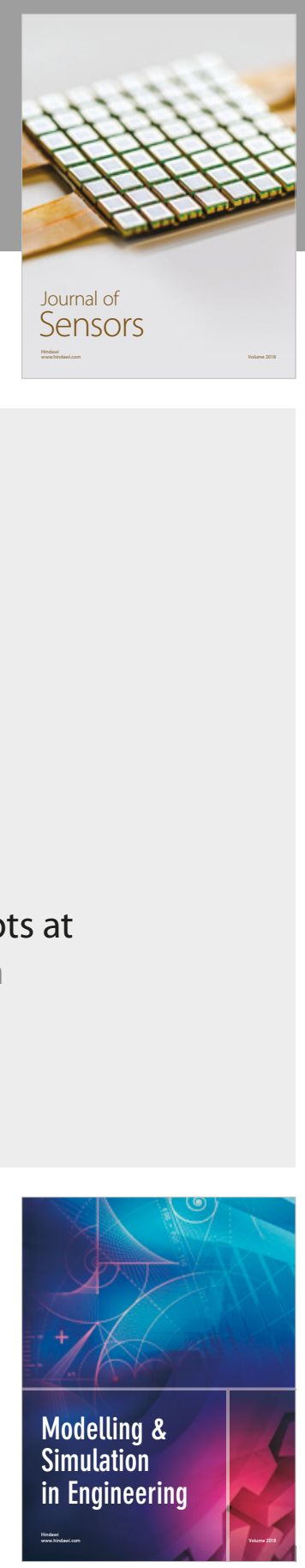

\section{Advances \\ Multimedia}
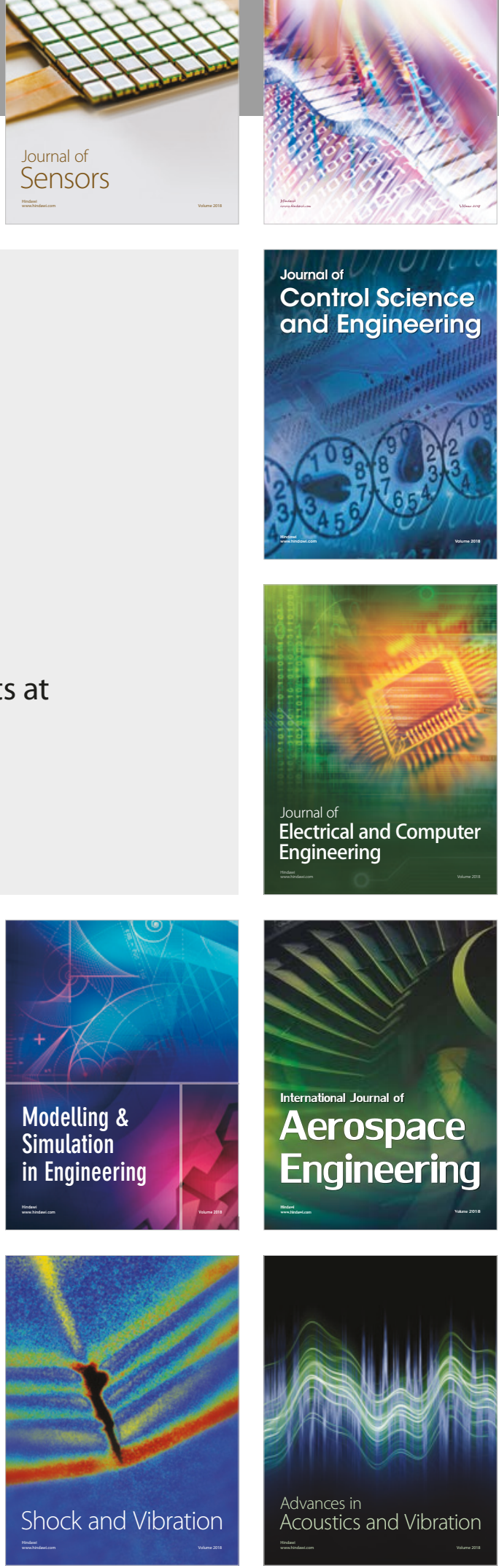